\title{
Erratum to: Characterization of secondary metabolite compounds correlated with the seasons in Artemisia princeps var. orientalis (Pamp.) H. Hara leaves using direct sample injection and gas chromatography-mass spectrometry: contribution to phytotoxicity
}

\author{
M. I. R. Mamun • A. M. Abd El-Aty •
}

Md. Musfiqur Rahman · Jeong-Heui Choi •

Kyeong Won Yun · Ho-Chul Shin · Jae-Han Shim

Published online: 10 April 2015

(C) The Korean Society for Applied Biological Chemistry 2015

Erratum to: J Korean Soc Appl Biol Chem (2015) 58(2): 173-183

DOI 10.1007/s13765-015-0020-3

The affiliation of one of the corresponding authors, A.M. Abd El-Aty, has been changed. The current affiliation is given in this erratum.

The online version of the original article can be found under doi:10. 1007/s13765-015-0020-3.

M. I. R. Mamun - Md. M. Rahman - J.-H. Choi · J.-H. Shim

Biotechnology Research Institute, Chonnam National

University, 77 Yongbong-ro, Buk-gu, Gwangju 500-757,

Republic of Korea

e-mail: jhshim@jnu.ac.kr

M. I. R. Mamun

Department of Chemistry, University of Dhaka,

Dhaka 1000, Bangladesh

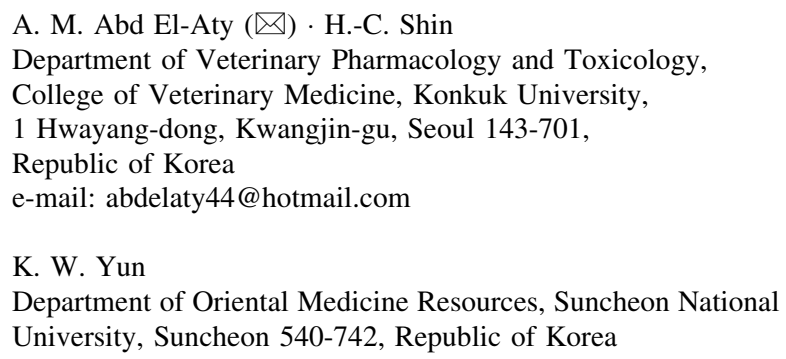

